\title{
Idaho National Laboratory Quarterly Performance Analysis - 3rd Quarter FY2014
}

\author{
Lisbeth A. Mitchell
}

September 2014

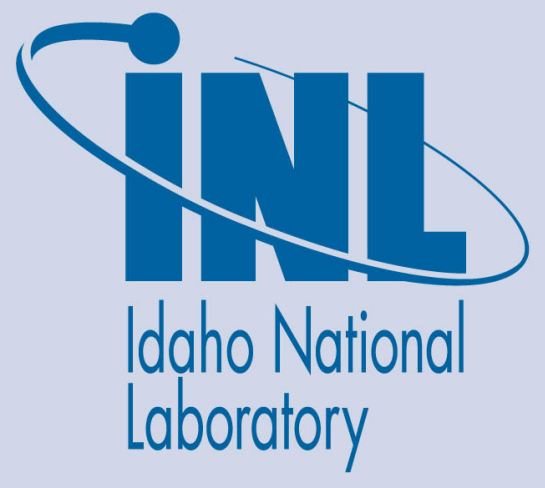

The INL is a U.S. Department of Energy National Laboratory operated by Battelle Energy Alliance 
DISCLAIMER

This information was prepared as an account of work sponsored by an agency of the U.S. Government. Neither the U.S. Government nor any agency thereof, nor any of their employees, makes any warranty, expressed or implied, or assumes any legal liability or responsibility for the accuracy, completeness, or usefulness, of any information, apparatus, product, or process disclosed, or represents that its use would not infringe privately owned rights. References herein to any specific commercial product, process, or service by trade name, trade mark, manufacturer, or otherwise, does not necessarily constitute or imply its endorsement, recommendation, or favoring by the U.S. Government or any agency thereof. The views and opinions of authors expressed herein do not necessarily state or reflect those of the U.S. Government or any agency thereof. 
INL/EXT-14-32891

\title{
Idaho National Laboratory Quarterly Performance Analysis - 3rd Quarter FY2014
}

\author{
Lisbeth A. Mitchell
}

September 2014

\author{
Idaho National Laboratory \\ Idaho Falls, Idaho 83415
}

http://www.inl.gov

Prepared for the

U.S. Department of Energy

Office of Environmental Management

Under DOE Idaho Operations Office

Contract DE-AC07-05ID14517 


\section{Contents}

Highlights

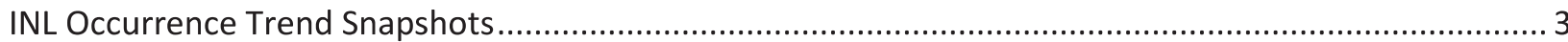

KEY LESSONS LEARNED ISSUED BY INL ORGANIZATIONS ................................................. 4

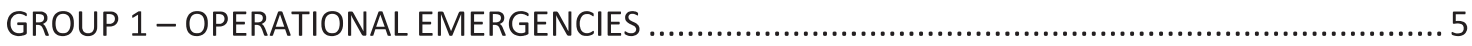

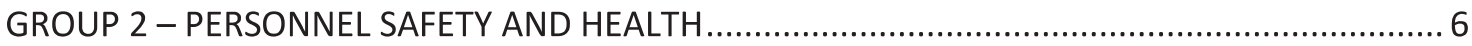

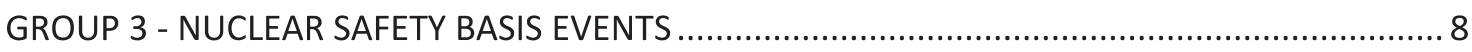

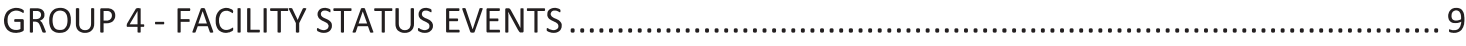

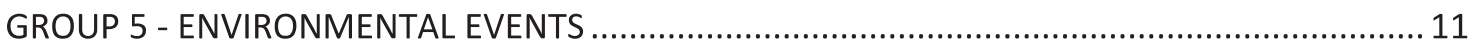

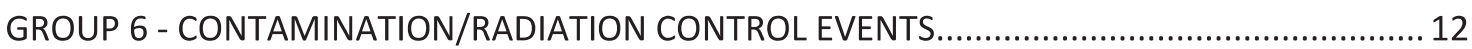

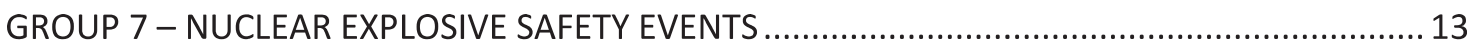

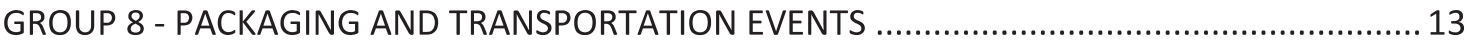

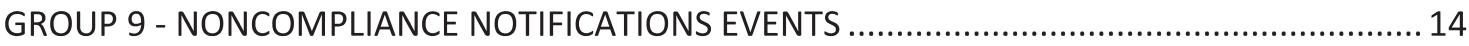

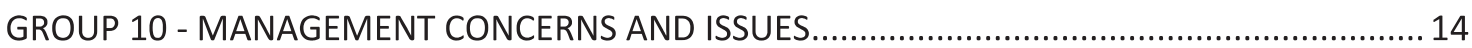

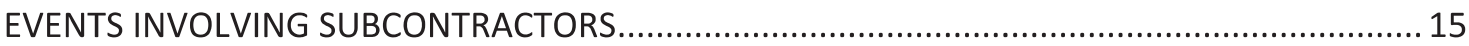

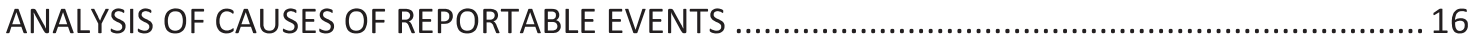

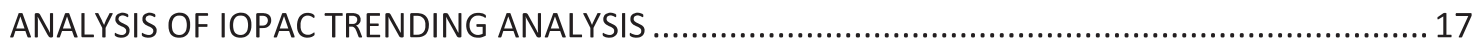


INL/EXT-14-32891

FY-14 3rd Quarter

This report is published quarterly by the Idaho National Laboratory (INL) Quality and Performance Management Organization.

The Department of Energy (DOE) Occurrence Reporting and Processing System (ORPS), as prescribed in DOE Order 232.2, "Occurrence Reporting and Processing of Operations Information," requires a quarterly analysis of events, both reportable and not reportable, for the previous 12 months. This report is the analysis of 61 reportable occurrences and 29 other issue reports (including not reportable events and Significant Category A and $B$ conditions) identified at INL from April 2013 through March 2014.

Battelle Energy Alliance (BEA) operates the INL under contract DE-AC07-051D14517.
Highlights...

The average number of occurrences reported at the INL each quarter has dropped this fiscal year from 19.5 to 12 . The rate of significant events (those reported as Operational Emergencies, Recurring Issues, and/or Significance Categories 1 or 2) is trending slightly upwards over the past two years; however the trend is slowing. As it is currently trending, the total number of significant events reported in FY-14 should be below those reported in FY13.

Over the past eight quarters, the average number of days between significant occurrences is decreasing and is trending downwards, indicating that significant events are occurring more frequently. An increase in the number of days between significant events is a positive trend.

This quarterly analysis reviews those events that were reportable through ORPS, events that did not meet ORPS reporting thresholds, some conditions tracked in LabWay, the causes of reportable events, and trending performed by the INL Operational

Performance Analysis Committee (IOPAC) group.

The report also provides a summary of the more significant Lessons Learned issued by INL.

\section{Occurrence Reporting Rates as of FY14 Qtr 1}
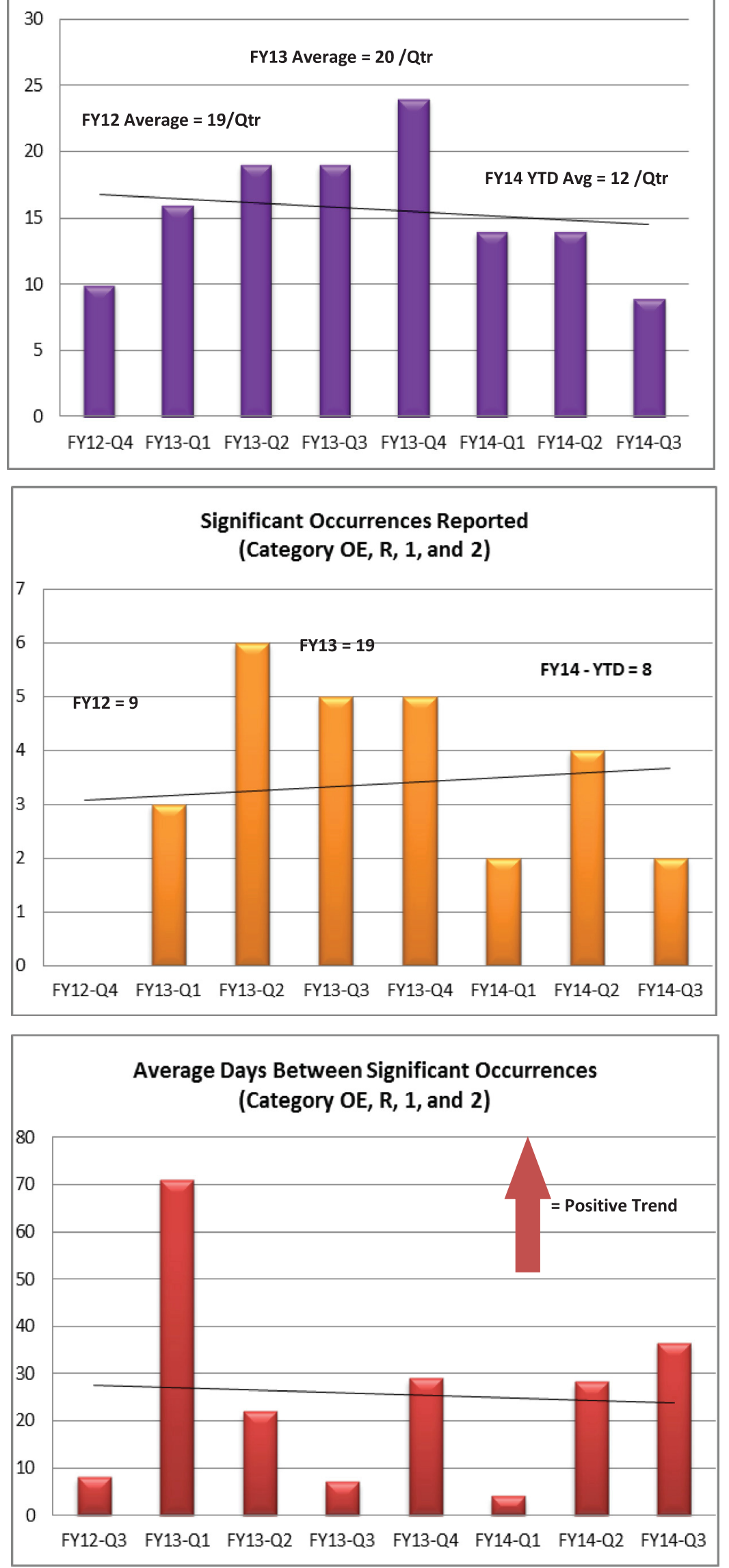


\section{INL Occurrence Trend Snapshots}

From 04/01/2014 through 06/30/2014, INL reported nine new events to DOE, in accordance with DOE Order 231.1B. These events are analyzed to determine commonalities related to: Operational Emergencies (Group 1), Personnel Safety and Health (Group 2), Nuclear Safety Basis (Group 3), Facility Status (Group 4), Environmental (Group 5), Contamination and Radiation Control (Group 6), Nuclear Explosive Safety (Group 7), Packaging and Transportation (Group 8), Noncompliance Notifications (Group 9), and Management Concerns (Group 10).

In addition, INL reported five additional events through Initial Notification Reports and three Significance Category B conditions through INL's local issues tracking software that did not meet the ORPS reporting thresholds. These events are also discussed and analyzed within this report.

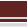

\section{TREND SNAPSHOT}

Occurrences by Facility: When anlayzing a 12 month average for each facility, the Advanced Test Reactor reported lower than their average of 8.75 reportable issues and MFC reported below their 12 month average of 3.25. All areas are reporting fewer events, as compared to the last 12 months. A similar decrease was seen regarding the number of Initial Notification Reports (INRs) submitted during the reporting period. This will be monitored to ensure reporting is not dropping off because of a desire not to report rather than because of fewer events occcurring.

ATR reported $67 \%$ of the events during this reporting quarter. Analysis of the nature and causes of all the reportable events is covered in other sections of this report.

\section{TREND SNAPSHOT}

\section{Occurrences by Reporting Criteria:}

INL has experienced the majority of events related to: Group 4, Facility Status (31\%), Group 2, Personnel Safety and Health $(27 \%)$, and Group 10 , Management Concerns, which accounts for $18 \%$ of events reported since FY-12. Analysis of all reportable events and any noted trends is covered in other sections of this report.
Occurrence Reports by Facility (Prior 12 Months)

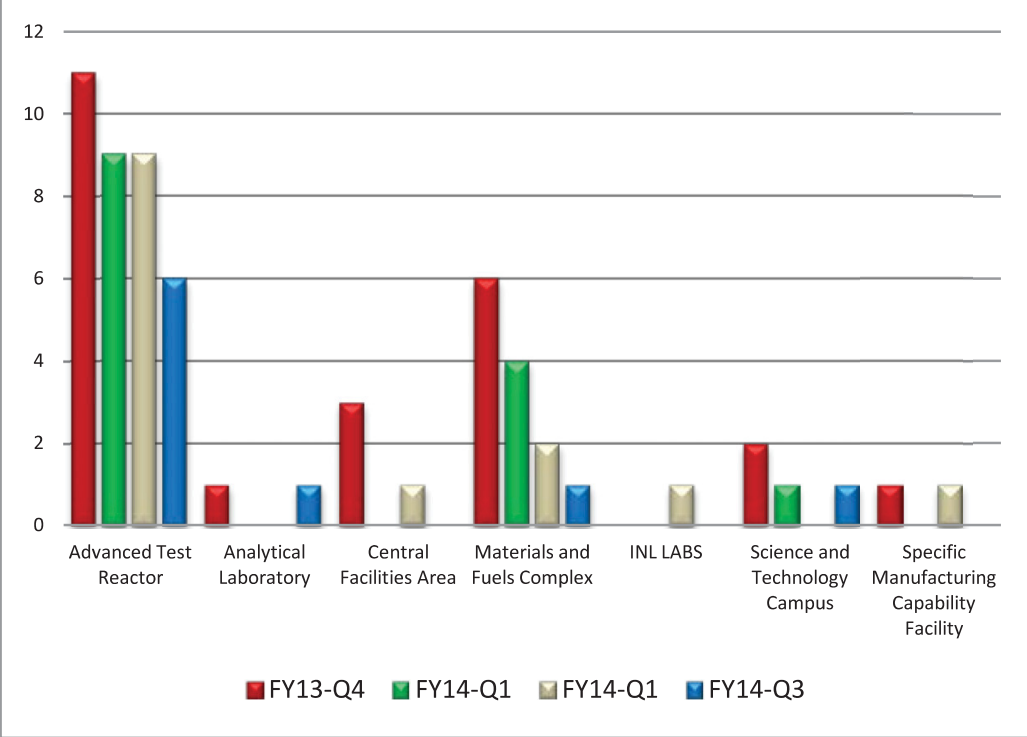

Occurrence by Reporting Criteria

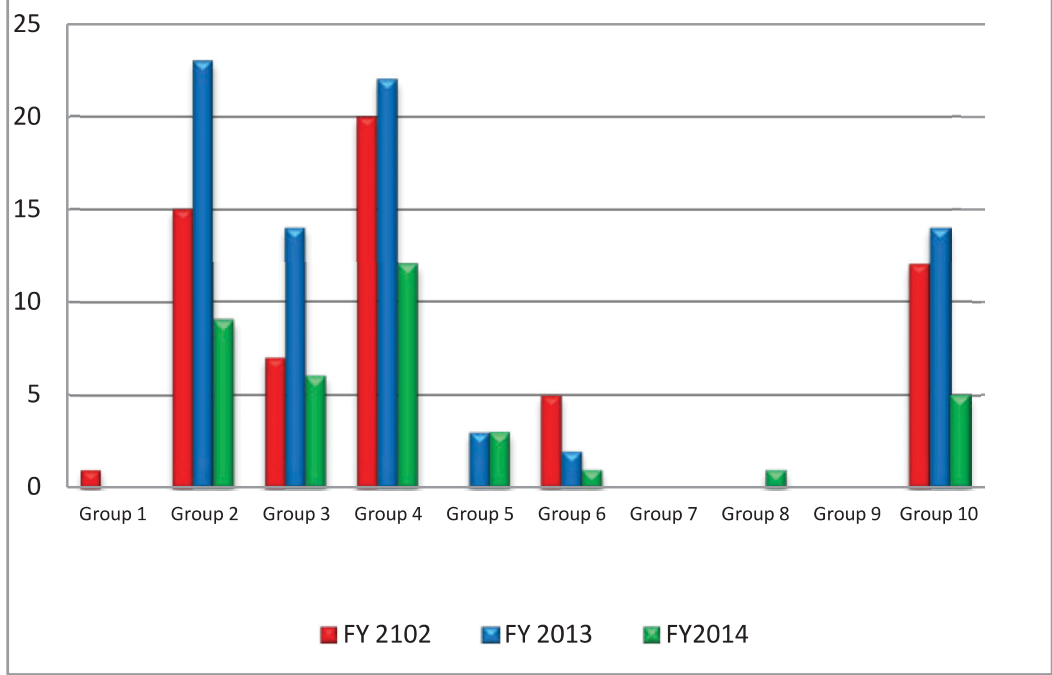




\section{TREND SNAPSHOT}

Lessons Learned Events: For the $3^{\text {rd }}$ Qtr FY-14, the use of Lessons Learned is showing increased improvement. Key factors in maintaining likelihood of events are for personnel to exercise high standards, with respect to behaviors, that can lead to events, by relating behaviors to actual events. To address this concern, Quality and Performance Management benchmarked Lessons Learned programs in place throughout the complex and developed actions aimed to improve Lessons Learned use across the INL. One improvement includes development and implementation of a standardized one page Lessons Learned format. Status of this effort will be updated during the $4^{\text {th }}$ Qtr FY-14.

The INL Lessons Learned Program is an integral part of the feedback and improvement processes required by DOE. Operational excellence requires the use of internal and external operating experience information (OEI) to minimize the likelihood of undesirable behaviors and promote noteworthy practices. Lessons learned, both positive and negative, are systematically evaluated and implemented to continuously improve performance. During the $3^{\text {rd }}$ Qtr FY-14, there were 68 Lessons Learned internally generated by MFC, EES\&T, ATR, and F\&SS.

Of those Lessons Learned, four were entered into the INL database to be shared. These are summarized below:

\section{Lab Worker Gets Splashed with Nitric Acid \\ Lesson 2014-1239 (Yellow - Caution)}

On February 19, 2014, a researcher was in the process of doing routine housekeeping in Lab 114 of the Radioanalytical Chemistry Lab (TRA-1627) at the ATR Complex. The work being performed was to composite and neutralize samples and standards inside of a radiological contamination area (CA) located inside of a chemical hood. The samples originated from various sample preparations and contained $1-5 \%$ nitric acid. The sample preparations were poured into a $1 \mathrm{~L}$ plastic bottle to composite and then neutralized using small aliquots of $50 \%$ sodium hydroxide. When handling a $50 \mathrm{~mL}$ polypropylene centrifuge tube, the tube disintegrated in the researcher's hand. A reflexive response to this event caused the tube contents to spray at the researcher. The researcher immediately felt a burning sensation in his neck/chest area and proceeded directly to the eyewash/safety shower $10 \mathrm{ft}$ away removing the prescribed gloves on the way.
The lesson to learn from this event is that long term chemical compatibility needs to be considered and carefully evaluated when putting chemicals into secondary containers. If there is any sign that container integrity is compromised, the performer should pause, evaluate the changed situation, consult others, and establish additional mitigations, if deemed necessary. In addition, when working in a chemical hood, sash placement can be critical as it is an additional barrier and adjustments should be made each time worker position is changed. Also, if laboratory personnel leave the workplace for extended periods of time, when they return from an extended absence, or when they leave the laboratory as a final action, the responsible lab space coordinator needs to have a comprehensive extent of condition discussion with the departing, returning, or replacement worker.

\section{Utility Operator Receives Electrical Shock from Unexpected Source}

Lesson 2014-1241 (Blue - Information)

A Utility Operator received a mild shock while performing a flame sensor safety check on a boiler at the Central Facilities Area (CFA). The check is performed once each 12-hour shift, usually taking less than five minutes to complete. The activity was performed in accordance with LI-262, "B-CFA-608 OilFired Boiler Operation." The operator removed the fire eye sensor (Flame Supervisory) while the boiler pilot was lit. Once the sensor had been removed, it was laid across the external end of the igniter (ignition lead). After the operator ensured the gas to the boiler had shut down, and the fire eye sensor no longer could see the pilot flame, the operator picked up the fire eye sensor to reinstall just as the boiler was trying to re-ignite and received a mild shock to his hand. Following the 
event, the operator was evaluated by medical personnel and released without restriction.

What can we learn from this event? To identify and mitigate hazards, work control processes are implemented with builtin lines of defense, which include administrative, hazard identification, engineering, and management oversight controls. When working with an energized system, hazard controls must be in place to ensure all forms of hazardous energy have been evaluated and the proper controls and/or PPE are in place to protect personnel. Additionally, personnel must be adequately trained with applicable procedures. Procedures, and steps/directions in the procedure, must be followed accurately and in the proper order.

\section{Failure to Follow Prescribed Hazardous Energy Control Procedures}

Lesson 2014-1680 (Blue - Information)

A Savannah River Remediation (SRR) Tank Farm/Effluent

Treatment Project (ETP) Shift Maintenance First Line Manager

(FLM) identified electrical heat trace in the insulation around a steam station pilot valve that was not part of the lockout established for the valve replacement. A lockout was established for isolating the steam hazard but not the potential electrical hazard. No controls were established in the work order task for the energized heat trace. No work was performed or was released to be performed on the valve.

We must remember that walk downs and reviews performed during development of lockout plans and pre-job walk downs by FLM before signing the lockout are safety cornerstones. Self-checking and peer checking are useful tools to ensure all hazards are identified and properly mitigated.

\section{Laborer Experiences Shock Sensation}

Lesson 2014-1681 (Blue - Information)

On May 27, three laborers were performing field work when a laborer experienced a potential shock sensation while standing on the back of a flatbed truck holding a metal post and hydraulic driver. The laborer's observations concluded that this must have been caused by the weather conditions at the time of the incident (cloudy overcast sky and distant lightning observed). The equipment used during the work activity was inspected and no source of electrical energy could be found. The laborers discontinued the field work and returned to CFA to find shelter from the weather conditions. A medical evaluation of the impacted employee concluded that there were no observable signs of health-related issues caused from the incident.

While we are unsure if the sensation experienced by the laborer was the result of a muscle spasm due to the repetitive nature of the work activity or if it was due to the changing weather conditions, we must be aware of both environmental and physical changes. Personnel working outdoors should understand that inclement weather conditions can present unexpected hazards. Before, during, and after a lightning strike to the ground, strong electromagnetic fields can induce transient electrical currents into man-made conductors, such as antennae, overhead lines, and metal fences.

\section{$3^{\text {rd }}$ Qtr FY-14 GROUP 1 - OPERATIONAL EMERGENCIES}

There were no operational emergencies reported during the $3^{\text {rd }}$ quarter of FY-14. The last operational emergency was reported in April 2012, when boron triflouride gas leaked from a neutron detector (NE-ID-BEA-INLLABS-2012-0003). The rate of occurrences of operational emergencies continues to trend at zero. 


\section{TREND SNAPSHOT}

Personnel Safety and Health Events: For 3rd Qtr FY-14, six events occurred that were related to personnel safety and health. One of these met reportable criteria and was communciated to DOE through ORPS. The rate of occurrence of reportable personnel safety and health events continues to trend downward. The one reportable event this quarter was related to a trip and fall. While this fall was not caused by icy walking surfaces, there have been a number of reportable slips/trips/falls in the past year that were caused by icy conditions. While this reportable event is similar in nature to the other falls, it is not considered repetative.

Personnel safety and health occurrences were the second most frequently reported event type, accounting for 17 reportable events in the last 12 months. One event categorized under the personal safety and health reporting criteria was reported during the $3^{\text {rd }}$ Qtr FY-14 and is summarized in the following graph. Additionally, four non-reportable events were also documented in the INL issues management software during the current quarter and are also summarized in the following graph.

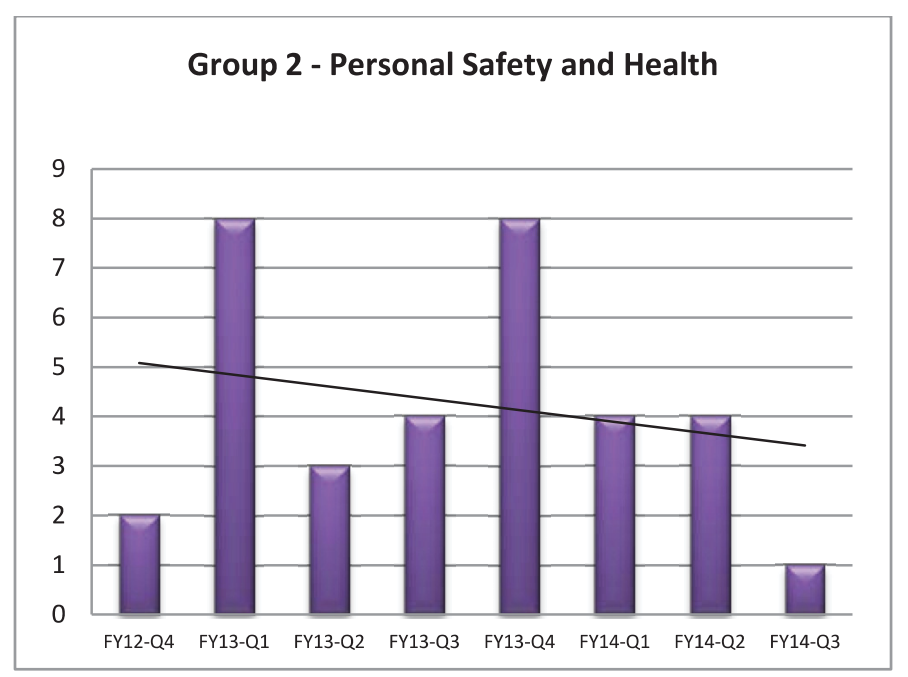

\section{Employee Breaks Bone in Left Foot While Walking} Through Parking Lot

NE-ID--BEA-STC-2014--0001 (Significance Category 3)

During the morning of April 10, 2014, an employee was

walking across the parking lot of the INL Administration Building (IAB) IF-606. The employee reported that her ankle suddenly turned causing her to fall. She felt a pain in the outside of her left foot and promptly reported to the Willow Creek Building (WCB) medical facility. X-ray images were obtained and the attending physician diagnosed a broken bone in the outside left foot. The employee also suffered a hair line fracture injury to her left wrist, which occurred as a result of the fall. The employee was seen by an off-site doctor and the wrist was immobilized.

Upon learning of the event, facility management made proper notifications to BEA and DOE management. The employee was questioned and did not recall stepping on anything that could have caused her to lose her footing. The parking lot was inspected for tripping hazards or uneven surfaces. None were identified.

Although no cause for the twisted ankle and fall was determined, we must remain aware of our surroundings and continually look out for ourselves and our fellow employees. The risk of falling can be reduced by wearing appropriate footwear, walking carefully, and ensuring your hands are free to help maintain balance. In addition, personnel need to recognize that the environment can quickly change, and they need to be able to adapt quickly and recognize changing conditions and the hazards that arise.

\section{Other Non Reportable Events}

There were four additional personnel safety and health concerns reported in LabWay during the $3^{\text {rd }}$ Qtr FY-14. These events did not meet ORPS reporting thresholds and are as follows: 
CO-2014-2831

A sub-contractor was working on a ladder and inadvertently stepped off the third step of the ladder to the floor. After stepping down, the employee felt pain in their leg/knee. The employee attempted to "walk-it-off" for a few minutes. The employee then requested an over-the-counter pain medication from the subcontractor clerk. The medication was provided, however, no information on the injury was shared and the employee never reported the event to their immediate supervision.

All employees must understand that it is important to promptly report any and all injuries to supervision. Unreported problems may develop into significant conditions if not treated and monitored.

\section{CO-2014-2448}

On May 7, 2014, a health physics technician (HPT) was placing items on portable shelving when he contacted the top of the frame and was scratched on his left wrist. As part of an accident investigation, all portable shelving in the area was evaluated and sharp corners were identified on five additional portable shelves. The shelving units' four corners extend slightly above the top shelf with very sharp angle iron. There are a total of 24 sharp corners on the portable shelving units located on level three of MFC-785. The shelving was recently acquired to assist HPTs store personal protective equipment. Upon discovery, the corners were covered to prevent further injury.

Employees should be aware of the potential for accidents in all work, not just work that is critical or inherently hazardous. In addition, when assembling equipment or shelving, employees should always look for, and mitigate any, laceration hazards before they cause injury to fellow workers.

\section{CO-2014-2665}

Three laborers were performing field work when one laborer experienced a potential shock sensation while standing on the back of a flatbed truck (see incident described in Lessons Learned 2014-1618). It is believed the incident was related to weather conditions. The need exists to analyze and establish criteria to determine when personnel can work or when they should be removed from the field during severe weather conditions. Because weather in Southeast Idaho can change unexpectedly, managers are encouraged to communicate to employees the expectation that they call a timeout or stop work and notify their immediate supervision when severe weather conditions arise that can impact the safety of a job.

\section{CO-2014-2754}

An HPT received a cut/scratch on their right ring finger when they were performing source checks on the Periodic Confirmatory Measurement (PCM) monitor in the Materials and Fuels Complex (MFC)-765 annex. In order for the HPT to complete source checks, their hand has to be close to the equipment's wire screens. If there are protruding wires their hand could come in contact with the wire, causing a cut or laceration hazard. A work request was submitted to inspect and to replace the detector screens for the PCM units in the annex building. No additional problems were found. Proper inspections performed by HPT instrument technicians during source checking will ensure the safety of workers using the detectors on a day-to-day basis.

Corrective actions that were implemented as a result of this injury include making light weight cut-resistant gloves or other similar hand protection available to HPTs when they are checking the screens. Personnel should also be aware of the potential for unknown hazards to be present when they place their hands in areas where a visual inspection may not identify hazards. 


\section{TREND SNAPSHOT}

Nuclear Safety Basis Events: Only one nuclear safety basis event was reported in the $3^{\text {rd }} \mathrm{Qtr} F Y-14$. The number of nuclear safety basis events decreased from last quarter and the rate of occurrence of nuclear safety basis is trending slightly downward over the past twelve months.

There were no similarities of the Nuclear Safety basis event that occurred this quarter, nor in its causes, organizations, or work groups, which would indicate an adverse trend or recurring problems within the last 12 months.

Nuclear safety basis events are the fourth most frequently reported event type, accounting for eight reportable events in the past 12 months. One event was reported during the $3^{\text {rd }}$ Qtr FY-14; the event is summarized below.

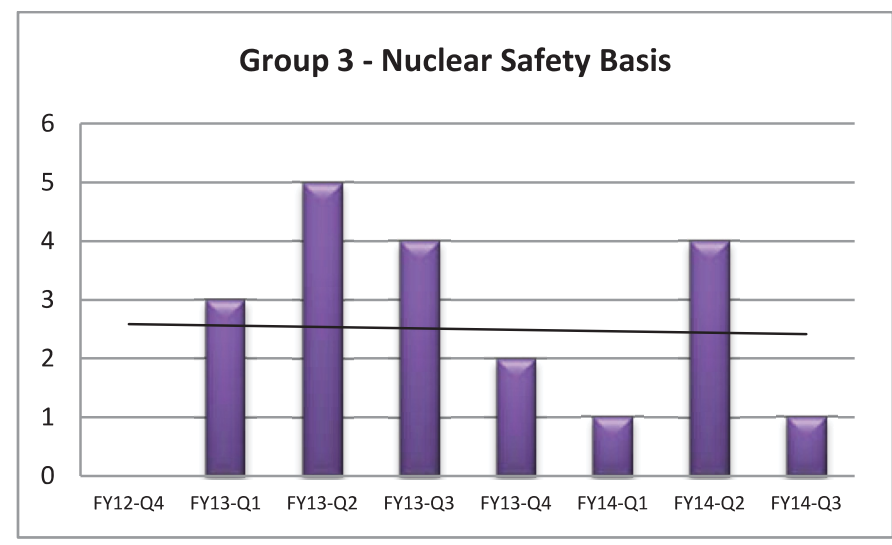

\section{Identification of Overstressed Bellows in the ATR Loop 1C-W Results in Potential Inadequacy of the Safety Analysis}

NE-ID--BEA-ATR-2014-0014 (Significance Category 2)

On May 22, 2014, a Potential Inadequacy in the Safety Analysis (PISA) was declared regarding the identification of overstressed bellows within ATR loop 1C-W. Safety Analysis Report (SAR)-153 credits the structural rigor of the ATR High Temperature Loop (AHTL) In-Pile Tube (IPT) (Loop 1C-W) per the design and construction of the loop to the appropriate American Society of Mechanical Engineers (ASME) Code.

The design specification stipulated an envelope tube [gas Annulus (He)] internal design pressure of 743 psig with an external pressure of 0 psig and an operating pressure of 590 psig helium. The gas annulus pressure represents the pressure upon the ATR IPT bellows. Having gas pressure present in the He annulus space allows the $1 \mathrm{C}-\mathrm{W}$ loop to operate at higher pressures, as compared to the standard loops, if a test sponsor requests a different operating environment for an experiment.

A technical evaluation was performed to evaluate the acceptability of the ATR IPT bellows design. The evaluation calculated the acceptable pressures and temperatures for the ATR IPT bellows, and showed that the maximum allowable pressure was 502 psig at $300^{\circ} \mathrm{F}$. This maximum pressure of 502 psig is less than the normal operating pressure of 590 psig.

The following interim controls were put in place to ensure the facility is operated within a safe condition:

- The inlet pressure of the ATR High Temperature Loop inpile tube shall be limited to 2500 psig, which is the same limitations imposed on standard IPTs.

- The maximum helium annulus pressure, in any in-pile tube with a subpile bellows assembly installed, is limited to a pressure of 502 psig.

A comprehensive action plan and lessons learned will be issued following completion of the cause analysis.

\section{Other Non Reportable Events}

There were no additional non-reportable events related to nuclear safety basis problems reported during the $3^{\text {rd }}$ Qtr FY-14 


\section{TREND SNAPSHOT}

Facility Status Events: Facility status events accounted for $44 \%$ of the events reported in the $3^{\text {rd }}$ Qtr FY-14. The rate of occurrence of facility status events continues to trend down over the past two years. Over the past 12 months, ATR has reported 15 events that fall into the Facility Status Events categories; seven of which were the result of a performance degradation of a safety significant component (SSC) when that component was required to be operable and five when the SSC was not required to be operable.

A review of the 15 SSC issues at ATR did not reveal a negative trend. Although six of the ATR SSC issues involved equipment associated with the Primary Coolant System (PCS), none were related to the same equipment. The other ATR issues involved different plant SSCs. In addition, there were no similarities of the four Facility Status events that occurred this quarter that would indicate an adverse trend or recurring problems within the last 12 months.

Events related to facility status have been the most frequently reported event type, accounting for 20 reportable events (15 events at ATR, 3 at MFC, and 2 at the REC Campus), in the past 12 months. Four facility status events were reported during the $3^{\text {rd }}$ Qtr FY-14 and are summarized below.

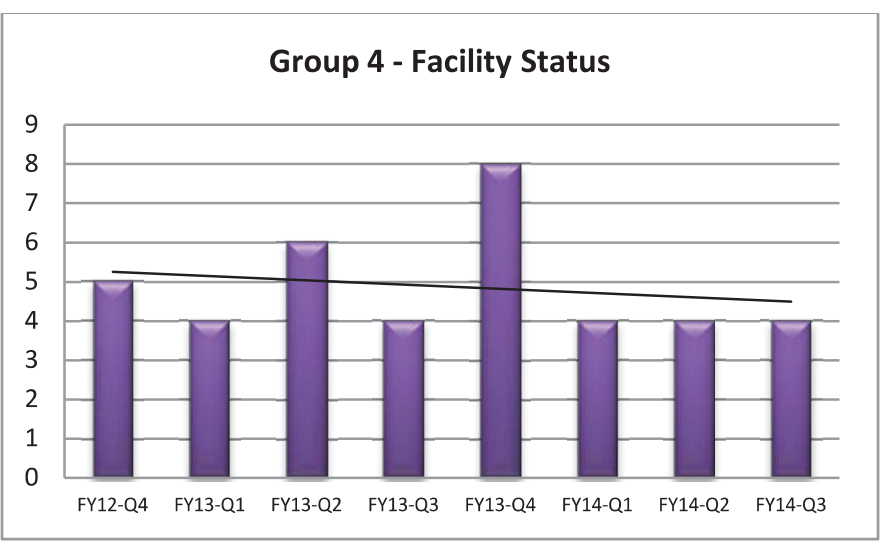

\section{Advanced Test Reactor (ATR) West Canal Bulkhead Seal Failure}

NE-ID--BEA-ATR-2014-0013 (Significance Category 3)

On May 19, 2014 at 1520, the ATR Canal Supervisor, making preparations for a cask handling evolution in the canal area, informed the ATR Shift Supervisor that air bubbles were visible from the west canal bulkhead. The seal pressure for one of the seals on the dual seal at this location indicated that the seal was leaking.
ATR Technical Safety Requirements (TSR)-186 Limiting Condition for Operation (LCO)-3.5.5, "Cask Handling and Irradiated Fuel Element Storage," was entered. The PISA ATR Complex-USQ-2010-741, "Isolation Requirements For Irradiated Fuel Element Canal Storage From The Canal/Reactor Vessel Interface," interim controls and Technical Evaluation (TEV)-284, "Evaluation of the Safety of the Situation for ATR RTC-USQ-2008-451," require that irradiated fuel elements in canal storage must be protected against potential canal draining accidents. Part of the protection provided to the irradiated elements in storage is to have isolation bulkheads installed in the canal with dual inflatable seals.

Cask handling activities in the canal were stopped. The cask was in a stable location on the main floor of the canal area and not in the actual canal when the seal failure was noted. Low pressure demineralized water makeup to the canal was confirmed to be available to the irradiated fuel storage section of the canal, and door/bulkhead 51 was shut to provide additional separation between the canal and reactor interface, as required by LCO-3.5.5, PISA ATR Complex-USQ2010-741, and TEV-284, Evaluation of the Safety of the Situation for ATR RTC-USQ-2008-451 interim controls. 
The lesson to learn from this event is to relentlessly pursue abnormal system indications to identify the cause and impact to safe operations. The failure of the canal bulkhead seal was identified by alert operations personnel and response was quick and compliant.

\section{Inadvertent ESF Actuation During Programming of Modification Testing of Pressurizing Pump Soft Starters at the ATR}

NE-ID--BEA-ATR-2014-0015 (Significance Category 2)

On May 22, 2014, pressure transients on the PCS resulted in three trips of the High Inlet Pressure Pump Shutoff system during testing of the newly installed soft starters on the ATR pressurizing pumps. The pump shutoff system protects the PCS from experiencing excessive pressure by automatically shutting off both the pressurizing pumps and the gland seal water pumps.

Multiple starts of the pressurizing pumps and the potential to reach the Engineered Safety Feature (ESF) trip point was anticipated and briefed by the watch team in preparation for the testing. The on-line pressurizing pump was tripped off and PCS pressure decayed to the standby pressurizing pump start set-point. The standby pressurizing pump started raising PCS pressure back to nominal; however, the pressure control valve could not control the pressure transient and the first overpressure event happened (ESF trip on Hi-Hi pressure).

The watch team conferred while PCS pressure decayed, the concern was for maintaining PCS pump (2000HP pumps) suction pressure to prevent cavitation. The decision was made to reset the ESF trip and try to control pressure. Following ESF reset, the pressurizing pump that was in STANDBY started, causing PCS pressure to increase again, the PCS pressure reached the Hi-Hi set-point and the ESF trip was received again.

At this point, the control room watch team decided the modification did not work and decided to reset the ESF and let the plant perform as designed. The ESF was reset, the standby pressurizing pump started, and PCS pressure increased to the ESF set-point. The pressurizing pumps tripped off-line from the ESF, PCS pressure decayed, the plant foreman reset the Loss of Coolant Accident (LOCA) trips to NORMAL to trip off the PCS pumps when we reached the Low pressure set-point.

The system testing was being performed to observe and gather data for changes in pressure control system response so adjustments could be made to the new soft starters and pressure control system tuning parameters.
ATR TSR-186 LCO 3.2.3.2, Pressurizing and Gland Seal Pump Shutoff System, was required to be operable and functioned as designed when a high pressure was reached during the pressure transient initiated by checking the pressurizing pump standby feature. The resulting trip of the PCS pumps also functioned as designed.

Causal to this event was a failure to integrate PCS system knowledge across several disciplines for the soft start design. The divergence from prior system design was avoidable. Additionally, a process for conducting infrequently performed tests or evolutions was not implemented. Test authors, work planners, and Operations Management failed to identify, in the outage scope, that the test was not simply a post maintenance test, but was, in fact, a unique test that used the PCS as a hydraulic test to determine an appropriate soft start ramp setting to avoid Distributed Control System (DCS) changes.

\section{Advanced Test Reactor (ATR) Scram From Experimental Loop 2B-SE}

NE-ID--BEA-ATR-2014-0016 (Significance Category 4)

On June 4, 2014, the ATR experienced an automatic scram (shutdown of the reactor) from Experiment Loop 2B-SE. The cause of the 2B-SE scram was due to a fault in a digital output module in the Loop 2B-SE remote processing unit (RPU).

Plant operations personnel responded in accordance with established procedures and all safety systems performed as designed when the scram was received.

The faulty digital output module was replaced, tested satisfactorily, and the reactor was restarted.

\section{Suspect / Counterfeit Bolts Discovered in Safety Significant Confinement Boundary/Shielding System} NE-ID--BEA-HFEF-2014-0001 (Significance Category 3) On June 16, 2014, at the Hot Fuel Examination Facility (HFEF), technicians were performing routine zone inspections when they identified potential suspect counterfeit fasteners $(\mathrm{S} / \mathrm{Cl})$ in piping flanges credited as part of the Safety Significant Main Cell Confinement Boundary/Shielding System. The following day, Engineering completed the evaluation of the $\mathrm{S} / \mathrm{Cl}$ fasteners and also identified additional fasteners that were unmarked and, therefore, considered ungraded fasteners in an application that did not meet system design requirements.

The HFEF Main Cell was taken to REPAIR MODE until an operability review of the affected system components could be completed. A risk based evaluation for $\mathrm{S} / \mathrm{Cl}$ discovered in use was conducted. The evaluation directed that the items be marked and replaced once maintenance on the equipment is performed. 


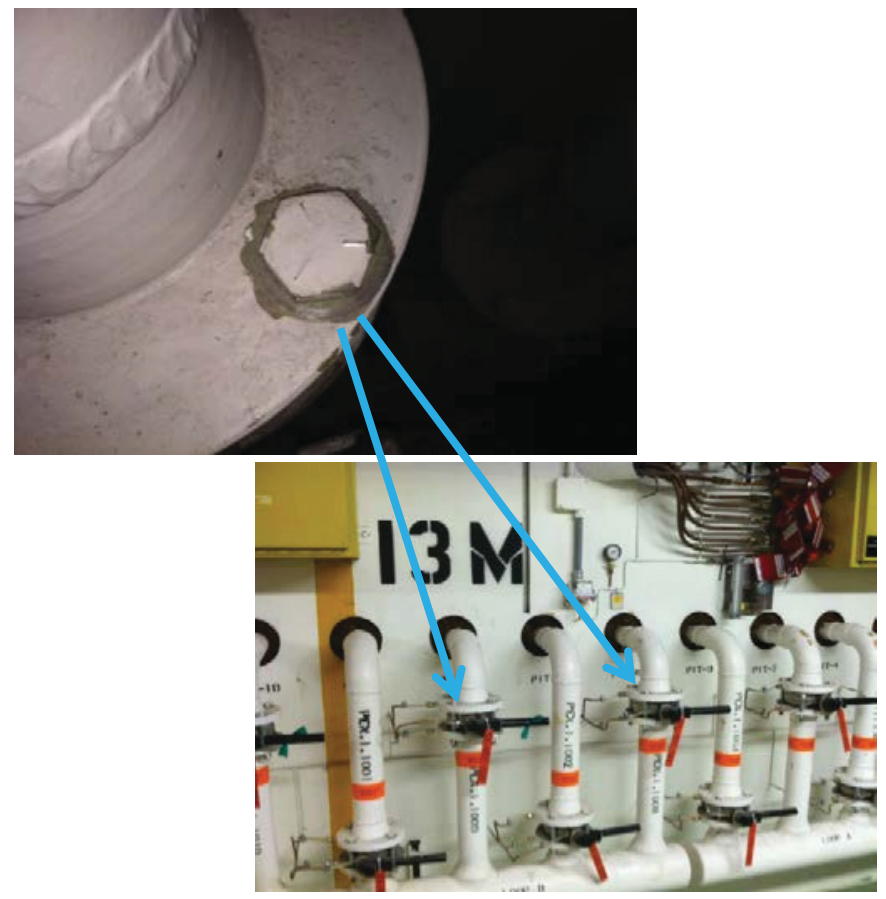

A lessons learned submitted on this event identified that plant personnel believed that the suspect or counterfeit bolts had been previously identified and evaluated, however, documentation supporting a previous discovery could not be located. The current INL process for identifying and controlling S/CI Items is LWP-13510 and includes processes to document the discovery and evaluation of suspect or counterfeit fasteners, as well as marking of suspect or counterfeit fasteners, as previously identified. To eliminate re-work, suspect or counterfeit items that are not immediately replaced, should be documented and appropriately identified in the field.

\section{Other Non Reportable Events}

No additional facility status events, that did not meet ORPS reporting thresholds, were reported in LabWay during the $3^{\text {rd }}$ Qtr FY-14.

\section{$3^{\text {rd }}$ Qtr FY-14 GROUP 5 - ENVIRONMENTAL EVENTS}

\section{TREND SNAPSHOT}

Environmental Events: There was one environmental event reported in the $3^{\text {rd }} Q t r F Y-14$. The rate of occurrence of environmental events continues to trend upwards, due to new 40 CFR, Part 63, Subpart ZZZZ (also known as Quad Z) requirements. The trend line displayed in the chart below shows an increasing trend over the past two years because of two evetns in the $3^{\text {rd }}$ Qtr FY13. When the data is plotted from FY13-Q3 through FY14-Q3, the trend is decreasing. Although the event reported this quarter is exact in nature to the environmental event reported the past three quarters, its occurrence is not indicative of an averse trend but of a known issue that is being addressed.

Events related to environmental problems are one of the least reported event types, accounting for only four events in the past 12 months one of which was reported in the $3^{\text {rd }}$ Qtr FY-14. This event is described in the following paragraph.

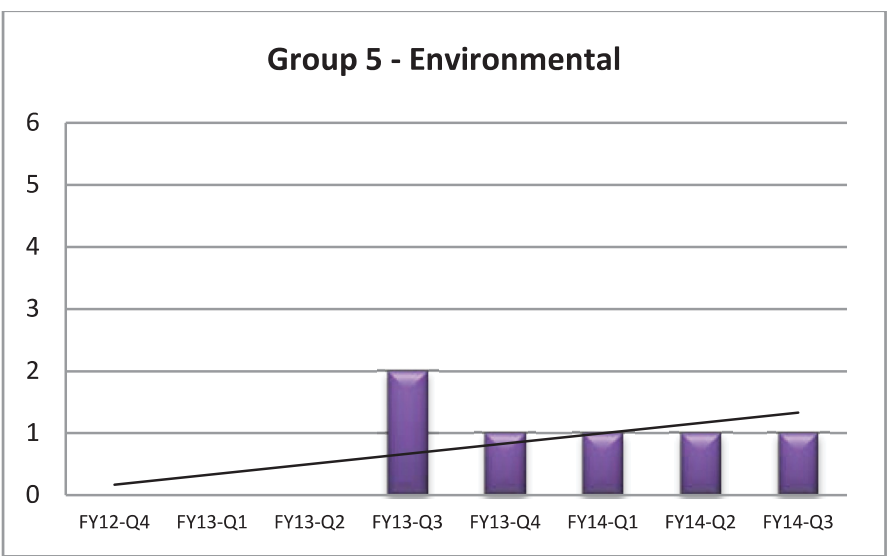




\section{Quarterly Report of Diesel Engine Startup at the Advanced Test Reactor (ATR)}

NE-ID--BEA-ATR-2014-0011 (Significance Category 4)

New environmental regulations, operation, and maintenance requirements for ATR Complex diesel engines are in effect: 40 CFR, part 63, subpart ZZZZ, National Emissions Standards for Hazardous Air Pollutants for stationary reciprocating Internal Combustion Engines (RICE), also known as Quad Z.

The following ATR Complex engines are non-emergency stationary RICE: Generators 670-M-42, 670-M-43, and 674-M-

6. Without installation of emissions controls, units $670-\mathrm{M}-42$, 670-M-43, and 674-M-6 do not meet the new emission standards for hazardous air pollutants that went into effect on May 2, 2013. INL has negotiated with the Idaho Department of Environmental Quality (DEQ) a Voluntary Consent Order (VCO) to replace units 670-M-42 and 670-M43 with a commercial power based uninterruptible power supply (UPS). When the UPS project is complete in 2015, all three units will be designated as emergency stationary RICE.

\section{Other Non-Reportable Events}

There were no additional non-reportable environmental events during the $3^{\text {rd }}$ Qtr FY-14.

\section{$3^{\text {rd }}$ Qtr FY-14 GROUP 6 - CONTAMINATION/RADIATION CONTROL EVENTS}

Events related to contamination and/or radiation control are some of the least reported event types at INL, these events have only accounted for two reportable events in the past 12 months. There was one reportable contamination/radiation control event that occurred in the $3^{\text {rd }}$ Qtr FY-14.

\section{Personnel Skin Contamination}

NE-ID--BEA-AL-2014-0001 (Significance Category 4)

On May 12, 2014, an HPT in the Analytical Lab (AL) at MFC discovered $\sim 100,000$ disintegrations per minute (dpm) beta/gamma contamination on the skin of his hand, using the default $10 \%$ instrument efficiency. The contamination was discovered during a routine hand survey following job coverage of the dilution of high-activity level flux wire dissolutions. Subsequent surveys and follow-up have been unsuccessful in pinpointing the exact source of the contamination.

Following discovery, the HPT immediately covered his hand and requested additional support. Smears and wipes were taken and decontamination was performed. Thorough surveys of all the areas where the HPT was performing work were performed with no additional contamination found.

Access to the laboratory was restricted until further surveys revealed safe levels and proper postings were in place. Isotopic analysis was conducted on smears taken on the HPT. The analysis strongly indicates that the hand contamination was of the same material (flux wire) being worked with on the day of the contamination event.

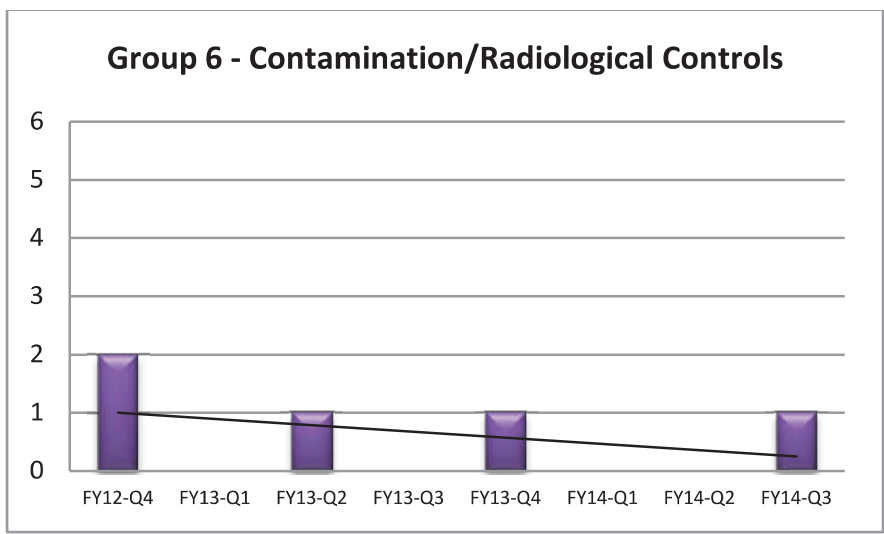

Other Non-Reportable Events

There was one additional non-reportable event related to contamination/radiation control; it is summarized below.

\section{CO-2014-1953}

On April 11, 2014, in the Fuel Cycle Facility (FCF), a loaded radioactive waste box was being removed from the facility for storage then shipment offsite. The box met High Radiation Area - Access Controls Required (HRA-ACR) controls per company procedure LWP-15019. The equipment operators arrived to support waste box removal activities. All personnel involved in the work activity were briefed, however, some personnel were already in the HRA-ACR, performing surveys and getting the box ready for the equipment operators. The equipment operators went down into the Room 118/Room 119 area to perform work.

While in the HRA-ACR, one of the equipment operators exited the area and reported he forgot his Electronic Dosimeter. Radiological controls personnel recognized that this resulted in a violation to company procedures, the Radiological Work Permit, and 10 CFR 835. The equipment operator was instructed to stay where he was (in a safe location at the top 
of the stairs) as the supervisor of the work was notified. At that time, the supervisor called a time out and all entrants in the HRA-ACR exited.

Analysis of an adjacent equipment operator's dosimeter indicated less than 2 mrem exposure at the time of discovery. The estimated exposure for the unmonitored equipment operator is estimated to also be near $2 \mathrm{mrem}$. The unmonitored equipment operator was wearing his optically stimulated luminescence (OSL) dosimeter which was collected to be sent to Dosimetry for counting to determine his official external exposure. Proper notifications were made.

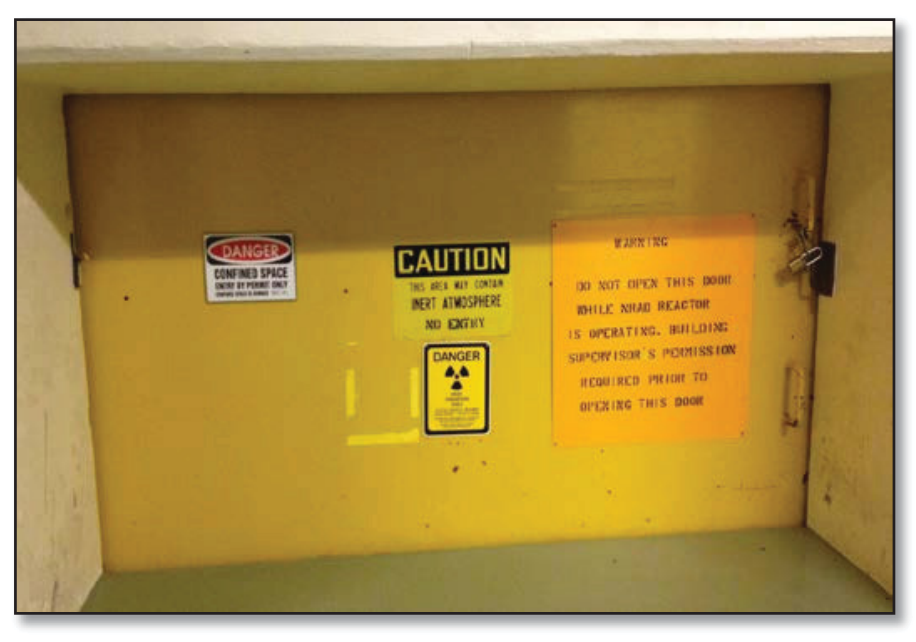

\section{$3^{\text {rd }}$ Qtr FY-14 GROUP 7 - NUCLEAR EXPLOSIVE SAFETY EVENTS}

There were no events related to nuclear explosive safety during the $3^{\text {rd }}$ quarter FY-14. BEA has never reported an event under this reporting criterion since taking over the contract for the INL in 2005.

\section{$3^{\text {rd }}$ Qtr FY-14 GROUP 8 - PACKAGING AND TRANSPORTATION EVENTS}

\section{TREND SNAPSHOT}

Packaging/Transportation Events: There were no packaging and transportation events reported during the $3^{\text {rd }}$ Qtr FY-14. The two year trend data shows an increasing trend because of the one event reported during the $1^{\text {st }}$ Qtr FY- 14 .

Events related to packaging and transportation rarely occur at INL; there has been one such event in the last two years. No packaging and transportation events were reported during the $3^{\text {rd }}$ Qtr FY-14.

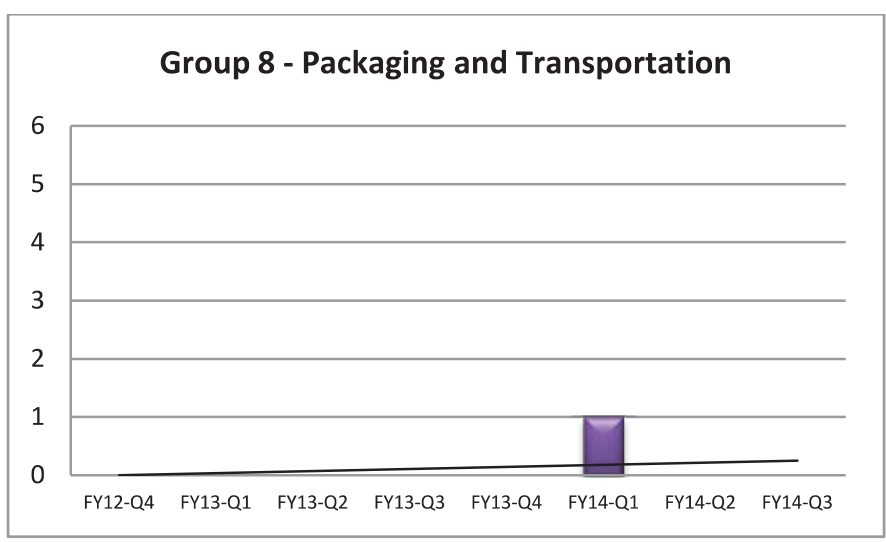


Noncompliance notification events are reported when the INL receives written notification from an outside regulatory agency that the site or an INL facility is considered to be in noncompliance with a schedule or requirement. Over the past 12 months, zero noncompliance notification events have been reported through ORPS.

\section{$3^{\text {rd }}$ Qtr FY-14 GROUP 10 - MANAGEMENT CONCERNS AND ISSUES}

\section{TREND SNAPSHOT}

Management Concerns and Issues: Only one event was reported in the $3^{\text {rd }}$ Qtr FY-14 under reporting critiera for a management concern or issue. The number of management concerns remained the same from last quarter and the rate of occurrence is trending slightly downward over the past 12 months.

Events reported as management concerns or issues accounted for $18 \%$ of the events reported over the past 12 months. One event was reported during the $3^{\text {rd }} \mathrm{Qtr}$ FY-14; this event is summarized below.

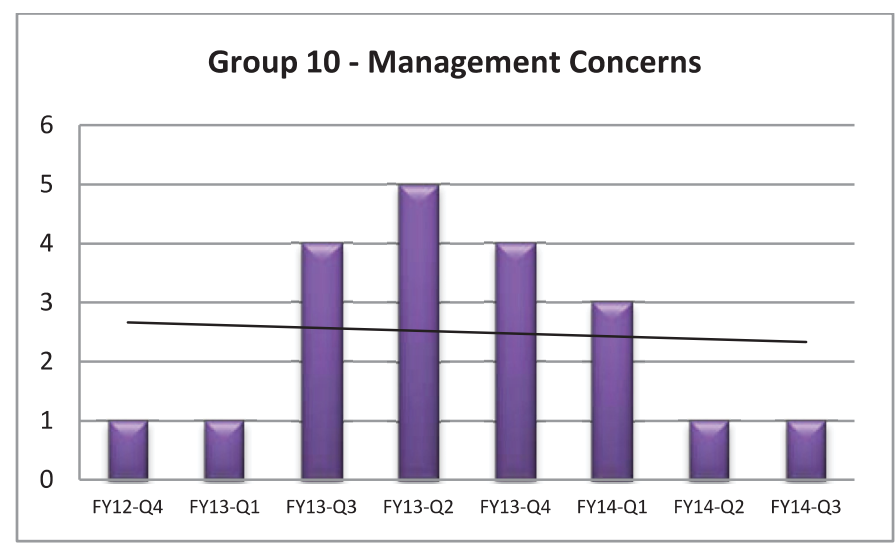

\section{ATR Enters Limiting Conditions for Operations (LCO) Due to Operator Inadvertently Placing Utility UPS in Bypass Mode}

NE-ID-BEA-ATR-2014-0012 (Significance Category 4)

On May 7, 2014, while taking rounds on the Utility UPS, an

ATR Lead Senior Reactor Auxiliary Operator (LSRAO)

inadvertently placed the UPS in bypass mode when he pushed a wrong button, realized what he had done, and pushed the intended button. The combination of these two buttons being pushed caused the Utility UPS to go into bypass mode. In bypass mode the equipment is no longer in a battery-backed condition. Realizing the error, the LSRAO reported this to the control room and Shift Supervisor.

The ATR canal level alarm system is powered from the Utility UPS and the crew entered the LCO 3.4.1 (C.3) for the Utility UPS Battery-Backed Power not available to the Canal Level Alarm System. Additionally, the crew entered LCO 3.5.6 (A), Canal Level Alarm System Inoperable due to the batterybacked aspect of the system no longer being in service. All actions and completion times were met to monitor ATR Canal level locally within 15 minutes and hourly thereafter.

This event did not originally meet any reporting criteria; however, after further consideration, management determined it to be a management concern and categorized it as such.

\section{Other Non-Reportable Events}

There were three additional non-reportable conditions that are being addressed as management concerns. These three conditions were screened as Significance Category B conditions and are summarized below.

\section{CO-2014-1794}

Conduct of Engineering was not followed for MFC-794 Experimental Fuel Facility (EFF) Westside Upgrade Project. A project was proposed to modify the west side of EFF to support further research work. The task entailed installing equipment at the West Side EFF, MFC-794. 
The Facility Manager asked if an Engineering Job (EJ) existed for the project in February 2014. However, the EJ was not created until the end of the project. Because of the failure to follow the established process, problems were discovered with technical and functional requirements, owner knowledge of the process, and configuration management.

An investigation into the issue found that the procedure was not followed, roles and responsibilities changed, project owners were not affiliated with the engineering department, and design inputs were not properly documented.

We can learn the importance of following engineering procedures when initiating a task such as the upgrade project at the EFF. Downtime and re-work can be avoided with proper planning and documentation.

\section{CO-2014-3274}

Based upon situations that developed during sizing operations of the AGR-2 experiment at ATR, several items were identified that need to be evaluated by Experiment Engineering. Immediate actions are being taken and a cause analysis is underway.
CO-2014-2779

In May 2014, Department of Energy-Idaho Operations Office (DOE-ID) identified that contrary to the requirements of DOE Order 232.2, INL's entry of event-related information in the ORPS database is not meeting timeliness requirements.

Of the 34 Significance Category 2, 3, and 4 ORPS events evaluated by DOE-ID during their assessment, 13 (38\%) were not categorized within the required two hours. The 13 events included six from ATR, four from MFC, and three from Research and Education Campus/Senior Training Council (REC/STC), etc. In addition, noncompliance to requirements for prompt submittal of written Notification and Final ORPS Reports were observed.

Based on information in the ORPS database, BEA was found to be ineffective in complying with the timeliness requirements of the ORPS system for documentation of event-related information on the INL contract. One or more timeliness requirement was not met in the documentation of 19 of 34 ORPS events, thus far, in FY-14.

BEA has begun to address this problem with the hiring of an ORPS Functional Lead to provide increased oversight of reporting requirements for ORPS.

\section{$3^{\text {rd }}$ Qtr FY-14 EVENTS INVOLVING SUBCONTRACTORS}

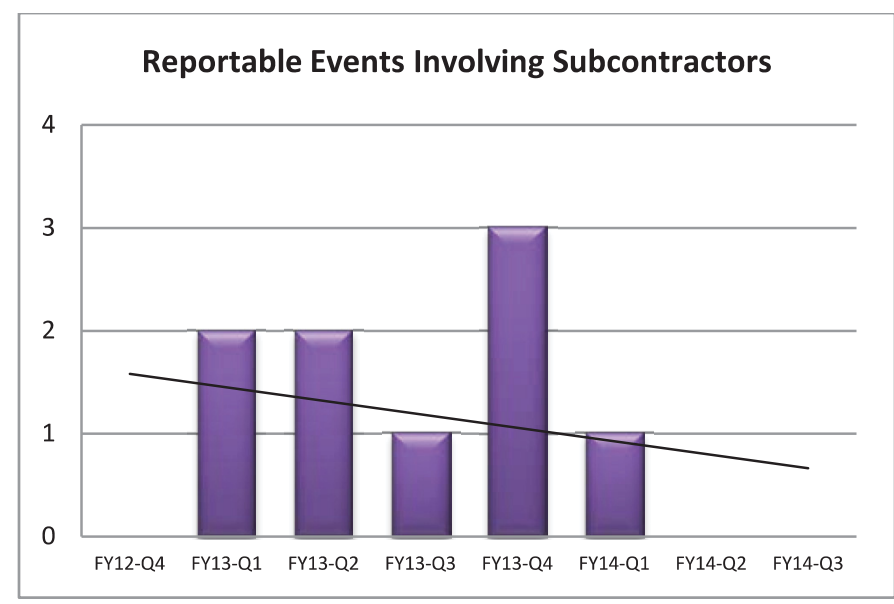

There have been nine events involving subcontractors reported through ORPS during the past two years; none were reported during the $3^{\text {rd }} \mathrm{Qtr} F Y-14$. One non-reportable event involving a subcontracted employee was reported under Group 2 - Personnel Safety and Health.

\section{TREND SNAPSHOT}

Events Involving Subcontractors: No events involving subcontract employees were reported during the $3^{\text {rd }}$ Qtr FY-14. The rate of occurrence of events involving subcontractors continues to trend downwards over the last two years. 


\section{$3^{\text {rd }}$ Qtr FY-14 ANALYSIS OF CAUSES OF REPORTABLE EVENTS}

Cause analysis results documented in ORPS were analyzed to determine trends, within the causes identified, over the past two years and during the past 12 months. The analysis shows that the majority of causes over both time periods can be attributed to human performance, management, and communications.

Over the past twelve months, human performance problems were most often associated with rule based errors including ignoring signs to stop, relying on pervious successes, and in using the wrong rule when solving problems. As was also reported last quarter, management problems were most often associated with less-than-adequate enforcement (or understanding) of policies and with less-than-adequate job scoping.
Communication problems were associated with written communications that included ambiguous instructions and those where the instructions were not complete or the situation encountered was not covered.

The chart below shows that there has been a sharp decline in the number of management problems for the last twelve months as compared to the causes reported over the past two years. At the same time, there has been little change in the number of problems caused by human performance. We can address this problem by having management spend time in the field, watching work and addressing incorrect behaviors before they lead to events.

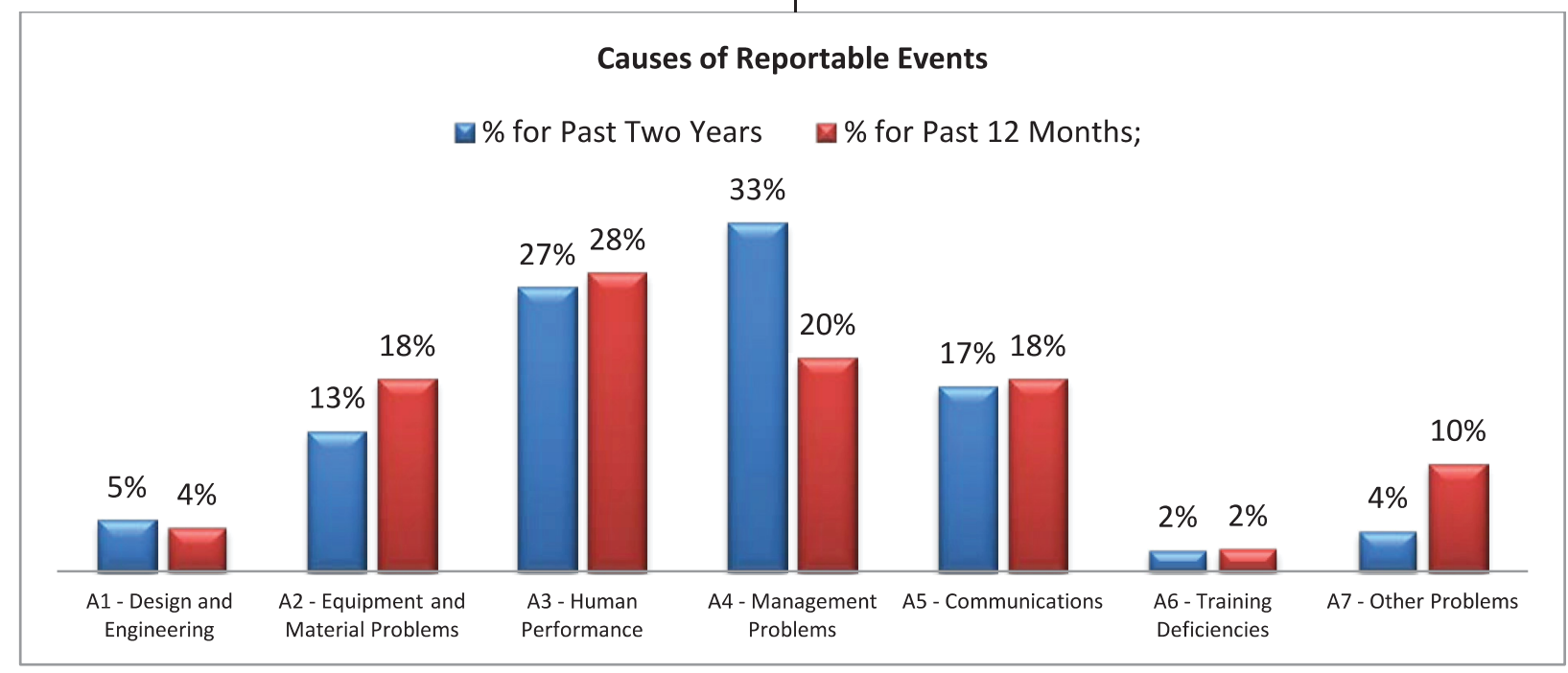




\section{TREND SNAPSHOT}

IOPAC Trending Analysis: For ${ }^{\text {rd }}$ Qtr FY-14, the eight mission centers (ATR, MFC, SMC, National Homeland Security, Nuclear S\&T, Energy and Environment S\&T, Facilities and Site Services, and Laboratory Protection) evaluated ORPS events, INRS, ICAMS, and LabWay issues for trending. In addition, analysis from the Radiological Controls Management System, the INL Work Management System, and Conduct of Operations were also presented by the IOPAC to INL Senior Management. Issues common across the INL and issues that continue to affect the INL are summarized below.

\section{Common Themes across the INL:}

- Trending of issues in the INL Issues Management System needs improvement. Trending teams need training so that there is some consistency in how trend codes are applied to issues.

- Improvements in implementation of conduct of operations principles are being noted across the laboratory.
- There is a need for increased management field presence.

- Legacy issues (those older than 200 days) need to be reviewed and validated for continued action.

- Personnel are stopping work when procedures are found to be incorrect or unclear.

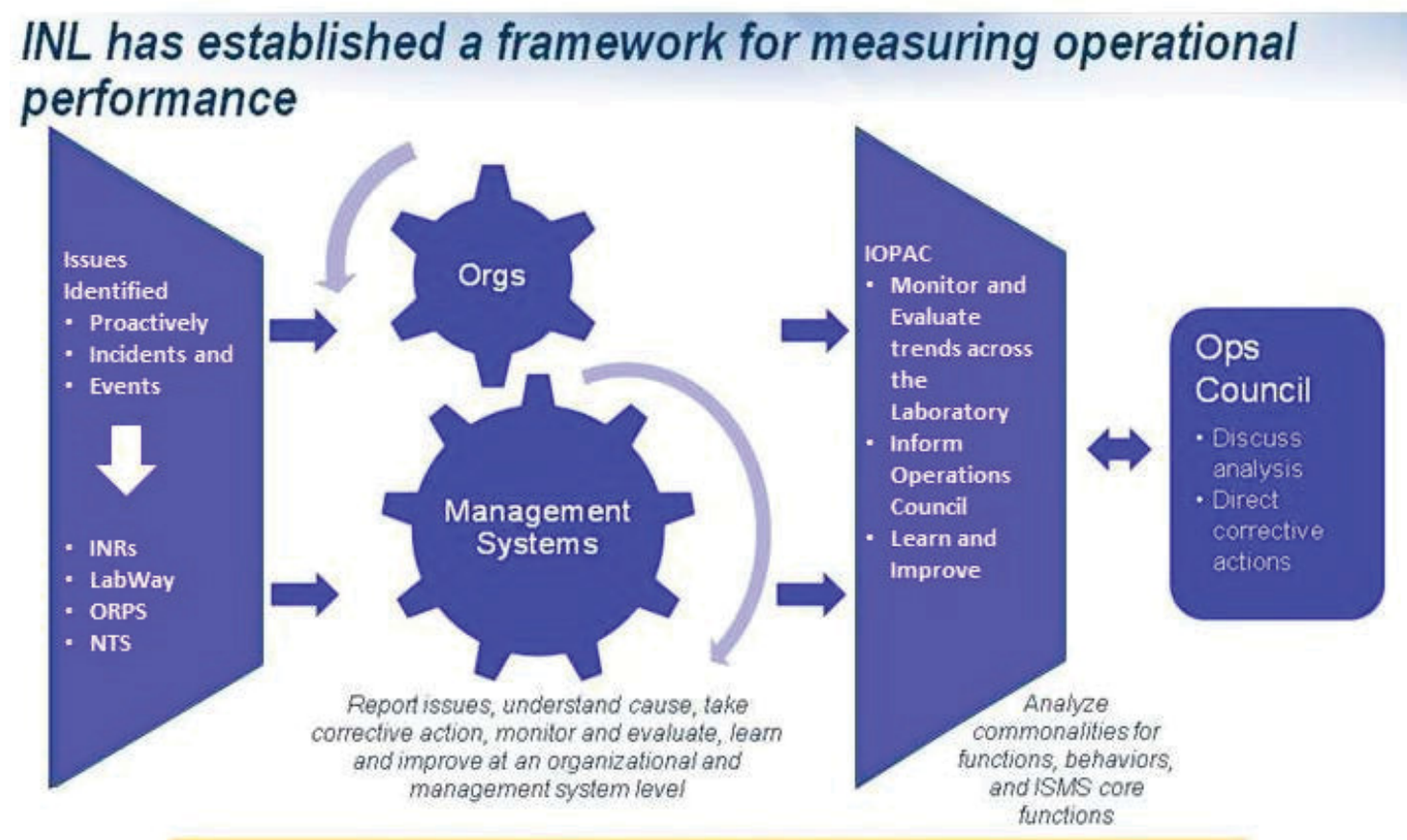

Fostering a Learning Culture

Figure 1. Framework for Measuring Operational Performance 


\section{INL Quality and Performance Management Expectations}

The INL mission involves performing and deploying world class research that meets the nation's needs in the areas of nuclear energy, other energy, the environment, and national security. Quality and Performance Management plays a critical role in supporting the INL mission. Our mission is to:

- Ensure we as a Lab know how we are doing and are improving our performance.

- Own and manage the Laboratory Issues Management System.

- Provide high quality QA program support for research and operations.

- Provide effective independent oversight.

"In order to be successful, we must be leaders, we must be competent, and we must be accountable. We must also exhibit the INL values of excellence, integrity, ownership, and teamwork."

- Chris Hott, Director-INL Quality and Performance Management

Idaho National Laboratory

INL Quality and Performance Management

P. O. Box 1625, Mail Stop 3206

Idaho Falls, ID 83415

INL/EXT-14-32891 